\title{
Teaching Ethics and Religious Culture in Quebec High Schools: An Overview, Contextualization and Some Analytical Comments.
}

\begin{abstract}
In 2008 Quebec introduced a new ethics and religious culture course. This marks a significant development in Canadian education as the mandated curriculum is intended for use in publically funded secular schools. In the past such courses have been in the domain of denominational schools. This new approach is examined in the context of the profound changes in Quebec society in recent years, typified by the sudden decline in the influence of the Roman Catholic Church. An overview of the curriculum is given, noting its basis as a particular type of phenomenological approach to the study of ethics and religion. The curriculum is analyzed against the theoretical perspectives developed by Moore and Wright. A number of issues on the scope of the study, the significant demands it places on students and teachers and how it critically engages with religious truth claims are examined
\end{abstract}

Key Words: Quebec, religious education, ethics, curriculum

Professor Richard Rymarz

Peter and Doris Kule Chair of Catholic Religious Education St Joseph's College, University of Alberta and Visiting Research Professor Australian Catholic University. 


\title{
Teaching Ethics and Religious Culture in Quebec High Schools: An Overview, Contextualization and Some Analytical Comments.
}

\author{
Abstract \\ In 2008 Quebec introduced a new ethics and religious culture course. This marks a \\ significant development in Canadian education as the mandated curriculum is \\ intended for use in publically funded secular schools. In the past such courses have \\ been in the domain of denominational schools. This new approach is examined in \\ the context of the profound changes in Quebec society in recent years, typified by the \\ sudden decline in the influence of the Roman Catholic Church. An overview of the \\ curriculum is given, noting its basis as a particular type of phenomenological \\ approach to the study of ethics and religion. The curriculum is analyzed against the \\ theoretical perspectives developed by Moore and Wright. A number of issues on the \\ scope of the study, the significant demands it places on students and teachers and \\ how it critically engages with religious truth claims are examined
}

Key Words: Quebec, religious education, ethics, curriculum

\section{Introduction}

One of the distinguishing features of the Canadian education in general is the lack of a uniform, national curriculum (Baldwin 2008). This is certainly evident in the approach taken to religious or moral education across the country (Peters 1998). For instance, in three provinces, Alberta, Saskatchewan and Ontario Catholic schools receive full funding and teach religious studies from a denominational perspective. In publically funded secular schools there is no common approach to about religion. In many provinces there is little or no provision for study of religion within provincially approved curricula (Stamp 1985). Quebec is an exception to this in that it has recently developed a new religious and ethics program for use in publically funded secular schools. This development can be seen against the backdrop of considerable change in Quebec schools in recent decades (Maclure 2003). The most notable of these was the abolition of 
religious based school boards which had operated with full public sponsorship, a situation that was paralleled in Newfoundland and Labrador (Fagan 2004). In 2008 the Ministry of Education in Quebec replaced the existing religious education programs in use in Quebec schools with a new common curriculum. The previous courses allowed for choice between three options; Moral education; Catholic religious and moral education; Protestant moral and religious education. These courses in turn came into being in public schools as a result of the 1997 constitutional amendment that removed for the state the obligation to provide denominational schools catering to Catholic and Protestant parents. In there place Schools Boards based on linguistic considerations were created. In what provided to be an intermediary measure public schools offered the three mentioned options.

The new, mandatory ethics and religious culture course is noteworthy for at least three reasons. Firstly, it is mandatory. No exemptions or alternatives for families who objected to the program were allowed. Secondly, the curriculum is stipulated for use in all schools in Quebec is they public or private. Lastly, the curriculum whilst non-confessional seeks to provide a comprehensive approach to ethics and religious education for all ethnic and religious groups in Quebec. In this article the social context for the new Quebec curriculum will be outlined as a prelude for as an overview of the new curriculum. I will focus my comments on some of the pedagogical features of the new curriculum drawing on two prominent paradigms in teaching about religion in contemporary contexts. From a North American perspective the work of Diane Moore will be used. Moore argues for an inclusive model of teaching world religions and from a European context the work of Andrew Wright will be used to provide a counterpoint analysis for the use of some phenomenological models for teaching about religion. 


\section{The social context of Quebec}

One emblematic theme in understanding contemporary Quebec is to recognize the seismic changes that have taken place there since the middle of the twentieth century. These changes, which have generated a wide and multifaceted literature, have been given the collective title the, Quiet Revolution (McRoberts 1975; Posgate and McRoberts 1976; Bibby 2004;

Gauvrea 2005). The key aspect of the Quiet Revolution was the sudden decline in the influence of the Roman Catholic Church on wider Quebec culture and on the lives of individual Quebecois (Bibby 1993B). In its place there evolved a robust secular mentality characterized by, amongst other things, a marginalization of religion to the periphery of personal and public life (Beyer 1993). ${ }^{\mathrm{i}}$ As is characteristic of fractured pillorized social structures that had heavily supported religious socialization, the collapse of Catholicism in Quebec was both unanticipated and tumultuous (Dekkar and Ester 1996). The legacy of Catholic cultural hegemony, however, are evident throughout the province, perhaps most notably in the history of educational institutions which had for centuries been under the control of religious organizations (Boudreau 1999; Dickinson 2008; Boudreau 2011). ${ }^{\text {ii }}$

Baum $(1991,24)$ put the suddenness of the decline of Catholicism and its cultural residue in these terms:

It is curious how quickly vast numbers of Catholics, trained and often fervent in their disciplined religion, shed the faith of their ancestors. While Catholicism remains visible in Quebec culture in its historical memoires, architecture, public symbols, practicing Catholics have become a minority.

The level of religious devotion of Quebecois prior to the 1960's can be measured by statistics such as Mass attendance (Bibby 1993A). In large parts of the province, this exceeded $80 \%$ of all Catholics at Mass on any given Sunday (O’Toole 1996). This peak number, however, quickly 
declined but such a formative religious culture did leave a type of historical memory that needed to be, at least, explained to younger and future generations (Hervieu Leger 2000). This chain of memory is a tenuous link to a meta-narrative that no longer figures in the lives of many who cannot, nonetheless, bring themselves to part from it entirely. It provides at once a link to the past and a reference point for the future ways. In educational terms it places before schools and similar agencies the considerable challenge of presenting a worldview that was once so dominant but which has now lost its hold although elements of this remain in the collective psyche. One illustrative example of this is given by Perrone (2008). She points out that even the most secular Quebecois still swears in "Catholic", that is, many curses and expletives are derived from terms used to describe the sacred within Catholicism. Another allegorical example of this type of seismic dislocation without a clear final resolution is one of the 137 recommendations of the Bouchard and Taylor report. They suggested moving the massive crucifix that dominates the legislative assembly in the Quebec parliament as this prominent display is no longer in keeping with a secular society (Bouchard and Taylor 2008, 28). The perplexing unresolved question, however, is where to move it to?

Over time other chains of memory emerge and individuals will re-orientate themselves to a new reality based on the bonds that have developed to replace the old ones. This process takes time and can be unsettling, so it is no surprise that governments in Quebec seek to keep alive the memories that they have. It is unlikely, however, that these bonds will ever become strong and compelling in the sense that they have a direct or decisive influence on how people live.

Christiano (2007) noted that while the historical place of Catholicism is recognized, most Quebecers had an ever-weakening connection with these historical roots. He observed, "whether future generations of Quebecers, more than ever imbued with the secular attitudes of their most 
accomplished artistic, intellectual, and economic elites (if not the critical foundations of those attitudes), will find such loose attachments to religious tradition either useful or ultimately satisfying is still an open question (Christiano 2007, 61).

While concentrating on the collapse of Roman Catholicism as the social and religious underpinning of Quebec and is concomitant rise of a new secular mentality amongst many Quebecois some attention must also be given to the increasing religious pluralism in Quebec. This is most obviously seen in the growth of communities that adhere to non Christian beliefs. Quebec has become home to an increasing number of new immigrants, many of whom do not have a common link with the province's religious history (Gagnon 2008; Farmer et al., 2010). For instance, many of the new immigrants are Muslims (Bibby 2009). In addition, there are longstanding communities of orthodox Jews in major cities such as Montreal as well as increasing numbers of south Asian communities who identify themselves as Hindu or Sikh. Bouchard and Taylor (2008) acknowledge that the rise of religious communities in an evermore self-consciously secular society such as Quebec can lead to tensions. In light of this they proposed a policy of reasonable accommodation to promote social harmony and cohesion. This policy is based on examining the claims of religious groups against the notion of what a secular society like Quebec could accommodate. Although no universal principles are adopted in the Bouchard and Taylor report, which was commissioned by the government of Quebec, they do offer a range of solutions to practical problems which define reasonable accommodation in the province. For instance, educational institutions are not expected to provide permanent prayer rooms but to respond to individual needs and requests on an ad hoc basis (Bouchard and Taylor $2008,41)$. In light of the discussion on the place of moral and religious education in public 
2012, Religious Education, 107(3), 295-310

schools Bouchard and Taylor $(2008,21)$ recommended that, "the government vigorously promote the new ethnics and religious culture course".

\section{Ethics and Religious Culture: An Overview}

One way of envisioning the new ethics and religious culture curriculum is to describe it as a typological approach emerging from a particular phenomenological framework. There are a range of phenomenological approaches to studying religion (Ratzinger 2004). The Quebec model places particular emphasis on sociocultural factors as opposed to ideological or dogmatic scrutiny of truth claims. Phenomenological studies of this type see religion as a generalized manifestation of human culture and as such are worthy of closer examination (Smart 1968). Religion is best understood here as an amalgam of diverse but common dimensions that can be examined in a rigorous and critical fashion (Smart 1974). Two common themes in this phenomenological approach are a specific understanding of the role of the teacher and defining the goals of the program in terms of growth in inter-religious knowledge.

In the Quebec curriculum the role of the teacher is seen in terms of an impartial, yet critically engaged, mentor. The task of the teacher is to assist students in their enquiry and to set the stage for an engaged and reflective learning environment. The teacher is responsible for ensuring that "the classroom is a place for doing research and engaging in dialogue" as stated in the official 2008 curriculum document, Quebec Education Program Secondary Cycle (QEPSE, 462). Importantly, teachers are expressedly instructed not to reveal their own particular beliefs or opinions.

Teachers show professional judgment imbued with objectivity and impartiality in order to foster students' reflections on ethical 
questions or understanding the phenomenon of religion. Thus to ensure against influencing students in developing their point of view, teachers abstain from sharing their opinions (QEPSE, 472).

The second common theme in this type of phenomenological approach is evident in the two overarching goals of the entire program. These are to foster in students an awareness of the common good and a willingness to engage in dialogue leading to an increase in knowledge of ethics and religious culture in a variety of forms. Within these general goals the specific scope and goals of the ethics component of the course are given as:

Ethics essentially consists in critically reflecting on the meaning of conduct and on the values and norms that members of a given society or group adopt in order to guide or regulate their conduct. (QEPSE, 462).

Instruction in ethics is aimed at developing an understanding of ethical questions that allow students to make judicious choices based on knowledge of the values and references present in society. (QEPSE, 462).

For the purposes of the study design religious culture promotes: "An understanding of the main components of religions that is built on the exploration of the sociocultural contexts in which they take root and continue to develop" (QEPSE, 461). The goal of the religious culture program is given as: "Fostering an understanding of several religious traditions whose influences has been felt and is felt in our society today. In this regard emphasis will be placed on Quebec's religious heritage" (QEPSE, preamble). It is worth noting that within this framework there is also an opportunity for teaching about secular worldviews. This is in recognition of the increasing number of students within Quebec schools who have no religious affiliation. In their 2005 document, Establishment of an ethics and religious culture program, the Quebec Ministry 
of Education acknowledged, "this program, intended for all students, must include learnings on currents of secular though [sic], even though it is not indicated in its name." (8).

Within this type of phenomenological framework for the study of ethics and religious culture, one common pedagogical approach is to divide the field into a number of sub categories or types and then to study each in turn (Moore and Habel 1982). This typological methodology builds up a diverse understanding as it allows for a range of areas to be examined. It also facilitates a communality of focus. This emerges because the types of phenomenon that are examined can be applied to a variety of religious positions or worldviews. In the Quebec curriculum religious culture is broken down into the following sub categories: sacred text; beliefs; teachings; rituals; ceremonies; rules of conduct; places of worship; works of art; practices, institutions and types of organizations (QEPSE, 461).

Within each of these categories teachers are given a framework on how best to develop a learning and teaching sequence. The categories are directed, nonetheless, toward the development of an understanding of religion as a complex phenomenon in modern society. For instance the goal of study in cycle one in secondary school is given as:

By the end of cycle 1 Students can understand forms of religious expression related to Québec's religious heritage, to fundamental elements of religious traditions and to representations of the divine and of mythical and supernatural beings. They can describe these forms of expression and demonstrate knowledge of their meaning and role. They can make connections with certain elements of the social and cultural environment both here and elsewhere in the world. They can draw out the shared and specific aspects of several of the forms of expression studied. They can demonstrate knowledge of certain behaviours that are suitable in the context of diversity, as well as the impact of various ways of thinking, being or acting on society. They are able to summarize their learning and assess the effectiveness of their process in order to make improvements, if needed (QEPSE, 534). 
To achieve this understanding teachers are directed to two interrelated outcomes which address an ethics competency and a religious culture competency. In each cycle a number of topics are identified as mandatory and these reflect the key goals of the unit of study. For example, in the secondary program cycle one: the ethics competency is given as:

Draw upon situations in which freedom and autonomy come into play, as well as situations involving concrete examples related to the social order so as to help students:

- reflect on different ways of viewing freedom, as well as its constraints and obligations

- reflect on different ways of experiencing autonomy and of understanding its

demands and the impact it has

- reflect on different ways of understanding the social order and reacting to it. (QEPSE,489)

In order to achieve this ethics competency students study forms of dialogue and conditions that foster dialogue as well as means for developing a point of view and means for examining a point of view. Teachers are provided with an overview of approaches to meet these expectations. In secondary program cycle one, for example, ways of facilitating dialogue such as conversations, discussion and narration are proposed. In cycle two of the secondary sequence the religious competency is given as:

Draw upon history, literature and art to encourage students to: - become aware that knowing a religious tradition requires understanding the significant events in its history - become aware that human beings have always asked themselves fundamental questions and that diverse religious traditions or currents of thought have offered responses to these questions - become aware that religious experience is an essential dimension for persons and groups affiliated with a religion - become aware that the religious character of certain works of art refers especially to writings, key figures and religious objects, and that these aspects can sometimes be found in secular works of art (QEPSE, 491). 
In order to achieve this religious competency students address the following areas; religions down through time, existential questions, religious experience and religious references in art and culture. Again guidance is given as to what teaching strategies could be used to achieve these goals along with the essential content to be covered. The curriculum points out, in several places, the distinction between compulsory and non-compulsory components. In terms of secondary cycle two a key aspect of compulsory content is the need to cover a variety of religious beliefs:

In developing the learning and evaluation situations, the teacher must ensure that:

- Christianity (Catholicism and Protestantism) is covered throughout each year of a cycle

- Judaism and Native spirituality are covered on a number of occasions in each year of a cycle

- Islam is covered on a number of occasions over the course of a cycle

- Buddhism is covered on a number of occasions over the course of a cycle

- Hinduism is covered on a number of occasions over the course of a cycle

- religions other than those mentioned above may be covered over the course of a cycle, depending on the reality and the needs of the class

- cultural expressions and those derived from representations of the world and of human beings that reflect the meaning and value of human experience outside of religious beliefs and affiliation are addressed during the cycle (QEPSE, 501).

\section{Ethics and Religious Culture: Some analytical comments}

One prominent feature of this new Quebec curriculum is the bold educational goals that it sets itself. Students are expected to understand religious beliefs, values and attitudes across a variety of cultural contexts. This poses significant challenges for teachers and students (Morris, Bouchard and DeSilva 2011; Van der Wee 2011). Moore (2007) sets out a model of religious education in a secular context and this too places significant demands on all those involved. A key difference in the approach outlined by Moore and what is described in the Quebec 
curriculum is the scope of the study. Moore (2007) focuses her attention on far fewer religions than the Quebec model. The rationale here is that religion is best understood not as an abstraction that can be broken down into a series of common phenomenon but as a lived and integrated whole. In Moore's work considerable effort is made to study one religion in detail taking care to investigate it in some depth and not precluding a critical aspect. For instance, in one of her programs, students undertake a study of Islam but this takes most of the academic year. In the Quebec model there is an explicit understanding that students will study a number of religious traditions as well as giving considerable time to the home tradition which in this case is the historical example of Catholicism in Quebec. This later focus presents some very contemporary challenges that are germane to a secular context. What is being studied is not so much a lived realty but a chain of memory, albeit modified from the concept developed by Hervieu Leger. In approaching the study of Catholicism, therefore, teachers must be aware of the new cultural reality in Quebec and teach about both traditional, or perhaps classical, Catholic beliefs but also how these have been supplanted by a new secular worldview amongst most Quebecers. Add to this the complexity of teaching about other world religions and you have very serious demands being made on teachers and students who take this course. Any world religion brings with it a diverse and complex range of beliefs, practices and internal culture as well as a range of historical expressions (Berling 2004). Take for example the complexity inherent in teaching about Judaism. The Quebec curriculum sets for itself the task of helping students understand the cultural diversity of modern Québec. This would include Orthodox and Hasidic expressions of Judaism which are relatively easy to engage with. There are visible minorities of Orthodox Jews in major cities especially Montréal but in addition there are larger numbers of much more secular Jews who are not easily described in the categories that apply to 
the Orthodox. The curriculum must address this interreligious diversity if it is to be true to its aims.

A serious concern in the Quebec context is what is to be made of the religious and ethical beliefs of the significant number of indigenous groups in the province? The arguments put forward about the complexity of world religions apply in greater force to indigenous groups, which in Quebec span Inuit groups in the north to Algonquin communities along the St Lawrence (Richards 2011). To do justice to these groups much attention must be placed on teaching about indigenous beliefs in terms that the local communities find acceptable (Bell 2004; Sarra 2011). There is a strong tendency in teaching on indigenous religious beliefs, practises and culture to present these in Eurocentric terms and to try to transpose them into a standard model when the content itself defies easily categorization (McPherson 2011). This is not to say that this is a hopeless task but rather that it requires special attention and considerable planning and sustained effort. In the new Quebec curriculum as well as attention to Catholicism, other religions, including strongly held secular views, teachers and students are expected to have strong content knowledge on indigenous religions. This places considerable demands on all involved in the successful implementation of the curriculum and raises a series of questions.

In the first instance is sufficient time allocated to the ethics and religious culture curriculum to be able to include attention to all of its demands? Are teachers adequately trained and properly supported to be able to deal with the complex content knowledge that is implicit in the study design? A number of European countries follow a curriculum that allows for a broad study of religion and ethics that have some similarities with the new Quebec curriculum (Meijer, et al., 2009). These countries, however, place significant expectations on teachers who enter training programs to teach these courses (Willaime, 2007). In Finland, for instance, religion 
teachers are expected to have a least a master's degree in a relevant discipline before they are allowed to teach about religion or ethics (Tirri 2009). In Quebec, what processes are in place to monitor and support teachers as they present the curriculum to students? Questions such as these are not intended to dismiss the goals of the curriculum but rather to help match the goals of the new curriculum with its outcomes. It is fair to say that following Moore's model there is some doubt about whether a study so broad in scope can be successfully delivered given the range of demands made on it.

Wright (2007) has pointed out that one significant difficulty in teaching about religion or ethics from some phenomenological perspectives, such as those in England, is that they do not sit easily with either the truth claims of religious groups or with a critical engagement with the subject. In England the study of world religions take place within the context of the wider curriculum and examines religious expression in a sociocultural context (Jackson and O'Grady, 2007). As such, there is some overlap between the approach taken there and the Quebec program. In essence, religion is seen as a phenomena to be studied by carefully apportioning it into various types or categories and then to take a comparative look at these categories across traditions. This is not, of course, how most religious traditions understand the epistemological basis of their beliefs. Islam for instance makes considerable truth claims as part of its assertions about authenticity. So do Christianity and Judaism. Examining religion and ethical statements made by religious people in a way that is contrary to the claims of religious traditions sets up a tension between the secular study of religion and how religious groups educate their own members. In addition, Griffiths (2001) has proposed that in order to gain a correct understanding of major religious traditions they need to be studied on their own terms. He points out that for orthodox Christianity this is a series of dogmatic beliefs about events that, according to the 
tradition, are rooted in history. In a sociocultural style of phenomenology what is stressed are not the truth claims of the religious traditions but rather there comparative aspect. While this may be acceptable to the framers of a secular curriculum does it give an accurate impression from the perspective of the religious tradition? What is being studied is not the religious tradition per se but rather a secularist view of it. In the Quebec curriculum this is illustrated by the very title of the program, namely, ethics and religious culture. For a secularist who is looking at a wide range of religions this is a very understandable approach. The question remains, however, does it do justice to religious assertions?

What adds to the poignancy of this issue in Quebec is the new course of studies in secular, public schools replaces a tripartite approach to religion with a compulsory single offering. In the previous model a generic moral education could be chosen or religious and moral education from a Catholic or Protestant perspective. The new approach collapsed these alternatives into what appears to be a remodeled form of the generic option. There is no exemption from the new course of study and this has generated much public discussion. A key concern here, articulated by various groups arguing that they would rather have no ethics or religious education than exposing their children to what is now mandated. ${ }^{\text {iii }}$ A way forward here could be to look at the contents of the ethics and religious culture course and to see if some parts of this could be utilized ion other areas of the existing curriculum. Many of the aspects of religious culture that are in the current curriculum, especially those that deal with Quebec's saturated Catholic heritage, could be moved to other parts of the curriculum such as social studies or history. In this all students could be exposed tot the history of the province without this being seen as a specifically religious study. What to do with the conscious study of religions is a more contentious issue that cannot be explored in this paper. Sufficed to say that Bouchard 
2012, Religious Education, 107(3), 295-310

and Taylor in their influential report recommended that serious efforts be made to explore alternate methods of faith education within the public system. This seems a recommendation well worth exploring.

The second aspect of Wright's critique of phenomenology is that it does not establish a sure epistemological foundation for a critical engagement with religion (Wright 2007). In this model the teacher is seen as an impartial guide who does not let his or her own views intrude on the subject matter. Whether such detachment is possible, or even desirable, in contemporary classrooms is an issue of some debate (I'Anson 2010). If we leave aside the broader legitimacy of this argument and focus on a pedagogical dimension, does such a claim of neutrality relativize the ethics and religion curriculum by making the teacher a conduit of information and not an active participant in the learning process? If the essence of a study of religion or ethics is an examination of associated phenomenon and then making a comparison between different beliefs on what basis can one challenge the claims of any tradition? Wright (2008) sees this as essential to the teaching and learning process, where education moves beyond the descriptive and into analysis. In a secular context it is, of course, very contentious to move into a critically engaged study of religion as this may easily degenerate into claims of partisanship but one group or another. It is far easier to take such an approach when the study of religion is being conducted under the auspices of a sponsoring religious group. For instance, an issue that is receiving coverage in the wider Quebec media is whether women should be allowed to cover their whole bodies when they are in public building such as schools, courts or municipal offices. This debate mirrors the discussion taking place in parts of Europe, most notably France (Croucher 2011). In order to critically evaluate this issue it could be preferable if this were done within the framework of an Islamic understanding of religion and its cultural accruements. This is not 
intended to be an apologia for the excesses of religion but rather providing a context where the issue can be explored within the specific parameters set by a religious tradition. Or to return to earlier points this is to allow religion to be seen and studied on its own terms. And to acknowledge that a study of a particular religion is a complex study as evidenced in this example by the various positions within Islam about what is appropriate clothing for believers.

\section{Conclusion}

The new ethics and religious culture course in Québec is a significant development in religious education in Canada. It represents an unprecedented attempt by a provincial government to give space in the curriculum of secular public school to the study of religion and ethics. In following a phenomenological model it an approach that has been followed in other parts of the world. At the same time the Quebec model raises a number of issues for further study and critical scrutiny.

Some of these issues are, in essence, practical. One concern is whether sufficient time been given to the new study in the school curriculums. This is a particularly pertinent issue for the study of native spiritualities which proceed from a different basis than western religions and as such need to be covered with methods that may require more time. Related to this point is the training given to teachers to teach a discipline which makes significant demands on content knowledge. As well as the comparative aspect of religion and ethics, teachers need to know a good deal about a variety of religions and ethical systems and how these can be explained to students without a strong religious socialization. 
A separate issue is how the new curriculum regards religion. It takes a particular type of phenomenological approach which has its strengths and weaknesses. It is not an approach to religion that many religion communities would advocate as it essentially sees religion through the prism of a secular worldview. How the educational authorities in Québec respond to this challenge is of considerable interest. In order to facilitate decisions in this regard what is now needed are empirically studies which examine the impact that the new curriculum is having on student learning. A further group of special interest are teachers of the new courses. A large scale, longitudinal examination of how they perceive the new curriculum - in situ - would be invaluable to further the ongoing debate.

\section{References}

Baldwin, D. 2008. Teachers, students and pedagogy: selected readings and documents in the history of Canadian education. Markham, Ont. : Fitzhenry \& Whiteside.

Baum, G. (1991). The Church in Quebec. Toronto: Novalis.

Bell, D. (2004). Sharing our success: Ten case studies in Aboriginal schools. Kelowna, B.C.: Society for the Advancement of Excellence in Education.

Berling, J. (2004). Understanding other religions: A guide for interreligious education. New York: Maryknoll.

Beyer, P. (1993). Roman Catholicism in Contemporary Quebec: The Ghosts of Religion Past? in W.E. Hewitt, (Ed), The Sociology of Religion: A Canadian Focus. Toronto: Butterworths.

Bibby, R. (1993A). Secularization and change' in W.E. Hewitt, (Ed), The sociology of religion: A Canadian focus. Toronto: Butterworths, 65-80.

Bibby, R. (1993B). Unknown gods: the ongoing story of religion in Canada. Toronto: Stoddart.

Bibby, R. (2004). Restless churches: how Canada's churches can contribute to the emerging religious renaissance. Toronto: Novalis.

Bibby, R. (2009). The emerging millennials: How Canada's newest generation is responding to change \& choice. Lethbridge, AB: Project Canada Books. 
Bouchard, G and Taylor, C. (2008). Building a future: A time for reconciliation. Quebec City: Government of Quebec. Obtained 20/8/2011 from http://www.accommodements.qc.ca

Boudreau, S. (1999). Catholic education: The Quebec experience. Calgary: Detselig.

Boudreau, S. (2011). From confession to cultural: Religious education in the schools of Quebec. Religion and Education, 38(3), 212-223.

Christiano, K. (2007). 'The Trajectory of Catholicism in Twentieth-Century Quebec', in Leslie Woodcock Tentler, (Ed), The Church Confronts Modernity: Catholicism since 1950 in the United States, Ireland and Quebec. (Washington D.C.: The Catholic University of America Press, 21-61.

Croucher, S. (2011). Religious misconceptions: The case of Muslims and Christians in France and Britain. London: Hampton Press.

Dekkar, P. and Ester, P. (1996). Depillarization, deconfessionalization and deideologization: Empirical trends in Dutch society. Review of Religious Research, 37(4), 213-226.

Dickinson, J. (2008). A short history of Quebec. Montreal: McGill-Queens University Press. Establishment of an ethics and religious culture program. (2005). Quebec Ministry of Education.

Fagan B. (2004). Trial: the loss of constitutional rights in education in Newfoundland and Labrador. St John's NL: ADDA Press.

Farmer, A., Ngouem, D., Madibbo, A. (2010). Current research compendium on francophone immigration in Canada. Montreal: Quebec Metropolis Centre - Immigration and Metropolis.

Gagnon, A. (2008). Quebec: State and society. Toronto: University of Toronto Press.

Griffiths, P. (2001). Problems of Religious Diversity. Oxford: Blackwell.

Hervieu Leger, D. (2000). Religion as a chain of memory. New Jersey: Rutgers University Press.

I'Anson, J. (2010). RE: pedagogy - after neutrality. British Journal of Religious Education. Vol. 32(2), 105-118.

Jackson, R and O'Grady, K. (2007). Religions and education in England. Historical roots, cultural context and recent developments, in Robert Jackson, Siebren Miedema, Wolfram Weisse and Jean Paul Willaime, (Eds), Religion and Education in Europe: Developments, contexts and debates. Munster: Waxmann. 
Maclure, J. (2003). Quebec identity: The challenge of pluralism. Montreal: McGill-Queens University Press.

McPherson, D. (2011). Indian from the inside: Native American philosophy and cultural renewal. Boston: McFarland.

McRoberts, K. (1975). Mass acquisition of a nationalist identity: Quebec prior to the Quiet Revolution. Montreal: McGill.

Meijer, W., Miedema, S and Van der Velde (2009). (Eds.) Religious Education in a World of Religious Diversity. Munster: Waxmann, 2009.

Moore, B., and Habel, N. (1982). When religion goes to school: Typology of relighion for the classroom. Adelaide: Tests in Humanity.

Moore, D. (2007). Overcoming religious illiteracy: A cultural studies approach to the study of religion in secondary education. New York: Palgrave Macmillan.

Morris, R., Bouchard, N and DeSilva, A. (2011). Enthusiasm and ambivalence: Elementary school teacher perspectives on the ethics and religious culture program. Religion and Education, $38(3), 257-265$.

O’Toole, R. (1996). Religion in Canada: Its development and contemporary situation. Social Compass 43(1), 21-43.

Perrone, J. (2008). How the French created Canada. Canada: Dragon Hill.

Peter, F. (1998). Religion and schools in Canadian Catholic education. Catholic Education; Journal of Enquiry and Practice, (1), 275-298.

Posgate, D. and McRoberts, K. (1976). Quebec: Social change and political crises. Toronto: McClellamnd \& Stewart.

Quebec Curriculum Ethics and Religious Culture (2008). Quebec Ministry of Education.

Richards, J. (2011). Aboriginal education in Quebec: A benchmark exercise. Toronto: C.D. Howe Institute.

Ratzinger, J. (2004). Truth and tolerance: Christian beliefs and world religion. San Francisco: Ignatius Press.

Sarra, C. (2011). Strong and smart: Towards pedagogy from emancipation: Education for first peoples. London: Routledge.

Smart, N. (1968). Secular education and the logic of religion. London: Faber\&Faber. 
Smart, N. (1974). The science of religion and the sociology of knowledge. New Jersey: Princeton University Press.

Tirri, K. (2009). Ethical dilemmas in conformation school experienced by Finnish confirmation schoolteachers, in Geir Skeie, (Ed), Religious diversity and education: Nordic perspectives. Munster: Waxmann.

Van der Wee, E. (2011). On the front lines: A teachers experience with Quebec's ethics and religious culture program. Religion and Education, 38(3), 241-256.

Willaime, J.P. (2007). Different models for religion and education in Europe, in Robert Jackson, Siebren Miedema, Wolfram Weisse and Jean Paul Willaime, (Eds), Religion and Education in Europe: Developments, contexts and debates. Munster: Waxmann.

Wright, A. (2007). Critical religious education, multiculturalism and the pursuit of truth. Cardiff: University of Wales Press.

Wright, A. (2008). Contextual religious education and the actuality of religions. British Journal of Religious Education. Vol. 30, No. 1, 3-12.

i Bouchard and Taylor (2008, p.20) defined four pillars of secular Quebec listed four pillars of secular Quebec: 1. The moral equality of persons, 2. Freedom of conscience and religion, 3. The separation of Church and State, 4. State neutrality in respect of religious and deep-seated convictions.

ii I refer to Quebec as a province for stylistic reasons. I acknowledge the wider debate within Canada as to whether Quebec is best described as a nation or a province.

iii To take one example, an article in the Calgary Herald from October 2008 captures the concern well in its heading "Basic freedoms Challenged by Religious Course". Obtained 24/9/11 fromhttp://www.canada.com/calgaryherald/news/story.html?id=2b8093d4-20a2-4b46-9996$615 \mathrm{fbdbb} 4 \mathrm{fd} 8$ 